1 Effective support following recurrent pregnancy loss: a randomised

2 controlled feasibility and acceptability study

3 Authors

4 Sarah Bailey ${ }^{\mathrm{a}, \mathrm{b}}$ - sarahl.bailey@soton.ac.uk

5 Jacky Boivin ${ }^{\mathrm{c}}$ - $\underline{\text { boivin@ } @ \text { cardiff.ac.uk }}$

$6 \quad$ Ying Cheong ${ }^{\mathrm{d}, \mathrm{e}}-\mathrm{y}$.cheong@soton.ac.uk

7 Christopher Bailey ${ }^{\mathrm{b}, 1}$ drcbailey@btinternet.com

$8 \quad$ Ellen Kitson-Reynolds ${ }^{\text {b }}$ - e.l.kitson-reynolds@soton.ac.uk

9 Nick Macklon ${ }^{\mathrm{d}, e,{ }^{2}}-$ nick.macklon@londonwomensclinic.com

a University Hospitals Southampton NHS Foundation Trust, Princess Anne Hospital, Coxford Road, 12 Southampton, SO16 5YA, UK

${ }^{b}$ Faculty of Health Sciences, University of Southampton, University Road, Southampton, SO17 1BJ, 14 UK,

' School of Psychology, Cardiff University, 70 Park Place, Cardiff, CF10 3AT, Wales, UK

${ }^{d}$ Faculty of Medicine, University of Southampton, University Road, Southampton, SO17 1BJ, UK

${ }^{\text {e }}$ Complete Fertility Centre, Princess Anne Hospital, Coxford Road, Southampton, SO16 5YA, UK

'Present address - Faculty of Health Sciences, University of Nottingham, Nottingham, NG7 2UK, UK

${ }^{2}$ Present address - London Women's Clinic, 113-115 Harley Street, London W1G 6AP, UK / Zealand University Hospital Copenhagen, Lykkebaekvej 1, 4600 Køge, Denmark

Corresponding author

24 Sarah Bailey - sarahl.bailey@soton.ac.uk

Abstract

28 Research Question

29 Is it feasible to perform a future definitive trial to determine the effectiveness of the Positive

30 Reappraisal Coping Intervention (PRCl) in improving the psychological well-being of women with

Design

recurrent pregnancy loss (RPL) during the early stages of a new pregnancy?

This mixed method study aimed to establish the feasibility of conducting a multicentre randomised controlled trial (RCT) to definitively test the effects of the $\mathrm{PRCl}$ on the psychological well-being of women with RPL. Participants $(n=75)$ were recruited to the study and at the point of a positive pregnancy test, 47 were randomised into two study groups. The intervention group received the $\mathrm{PRCl}$ and weekly questionnaire assessment (Hospital Anxiety Depression Scale and Weekly Record Keeping Form (WRK)) to monitor psychological well-being, the control group received the same questionnaires. Nested within the RCT was a qualitative process evaluation 
1 (QPE) exploring participants' subjective experience of study methods and the intervention. The

2 study was conducted over a two-year period between 2014 and 2016

4 Results

5 This study successfully gathered knowledge about the feasibility aspects of conducting a future multi-centre definitive study to determine the effects of the PRCl on the psychological well-being of women with RPL. Participants were receptive to its use and the intervention appeared to

8 convey benefits with no apparent downside.

9 Conclusions

10 The study concluded that a definitive RCT of the PRCl is possible and that the model of care already has the potential to be made more widely available as a safe, low cost, convenient and easily deliverable intervention to provide much needed support to a vulnerable patient population.

15 Recurrent pregnancy loss, Anxiety, Randomised controlled trial, Feasibility

Introduction

Recurrent pregnancy loss (RPL) is currently defined as the loss of three or more pregnancies

within the UK (RCOG 2011). However, other countries have adopted different definitions and the recently published European Society for Human Reproduction and Embryology (ESHRE) guideline suggests that RPL should be considered after the loss of two or more pregnancies (ESHRE 2017). The early stages of a new pregnancy, when confirmation by ultrasound scan of an ongoing and viable pregnancy is awaited, represent a particularly challenging period for women affected by this condition. Previous studies have indicated that this waiting period is associated with high levels of distress due to the anxiety of possibly experiencing a further miscarriage (Ockhuijsen et al. 2013a; Ockhuijsen et al. 2014c; Ockhuijsen et al. 2015). However, limited support and counselling is available during this difficult period and many are left to manage these distressing emotions without coping support. While some women seek frequent confirmation of viability by ultrasound scans, this approach is not feasible in most clinical settings, and appears to be of limited efficacy in reducing anxiety (Bailey et al. 2019). An alternative approach may be to provide the woman with tools that can help her cope with this period. technique, based on the principles of positive reappraisal. It has been shown to be effective at 
fertilisation (IVF) treatment (Lancastle and Boivin 2008; Ockhuijsen et al. 2014a, b). It comprises

2 an explanatory leaflet describing positive reappraisal coping and its potential benefits and 10

3 positive reappraisal statements that users read at least twice a day to stimulate this form of

4 coping (Figure 1). For women who have experienced RPL the waiting period in the early stages of

5 a new pregnancy shares many characteristics (unpredictable, uncontrollable, immense personal

6 significance) with the waiting period fertility patients experience after IVF, suggesting that the

$7 \quad \mathrm{PRCl}$ may also provide a potentially valuable supportive intervention for this patient group.

8 The essence of positive reappraisal coping is that it 'sustains the coping process through

9 increasing positive mood, via cognitive processing' (Lancastle and Boivin 2008). In view of the

10 overwhelming anxiety and despair women with RPL can experience during the early stages of a

11 new pregnancy, they might find this concept difficult to understand and be sceptical about

12 whether the $\mathrm{PRCl}$, a self-managed intervention, is able to make them feel more positive.

13 Therefore, to assess the potential value of the PRCl as a means of improving psychological well-

14 being, a study was designed to assess the acceptability of the intervention and the feasibility of

15 conducting a future large scale randomised controlled trial (RCT).

16 Effective feasibility or piloting work can anticipate difficulties with acceptability, compliance,

17 delivery of the intervention and recruitment and retention (Craig et al. 2013). Correspondingly, a

18 recent review concluded that the feasibility phase prior to an RCT helps to maximise the

19 likelihood of researchers evaluating the optimum intervention utilising the most appropriate and

20 proficient recruitment processes and trial design ( $O^{\prime}$ Cathain et al. 2015). Much of the literature

21 that examines the theory around such studies, uses the terms feasibility and pilot studies

22 interchangeably and the language used to describe the preliminary stages of a large-scale

23 definitive study remains inconsistent. However, the significant factor that connects the

24 synonymous use of the terms 'feasibility' and 'pilot' study appears to be that both types of study

25 address the uncertainties of study design and lay the foundation for a future definitive RCT. A

26 fundamental aim of a feasibility study is to determine whether it is possible to successfully deliver

27 a study in the proposed context (Bowen et al. 2009). Feasibility studies, therefore, play an

28 important role in establishing appropriate study design to support successful study completion

29 and may provide an indication of likely efficacy of the intervention.

30 The primary objective of this study was to establish the feasibility and acceptability of performing

31 future exploratory and definitive trials to determine the effectiveness of the $\mathrm{PRCl}$ in improving the

32 psychological well-being of women who have experienced RPL during the initial waiting period (1-

3312 weeks) of a subsequent pregnancy. 
2 Study Design

3 Between February 2014 and March 2016, women with a history of RPL were recruited to

4 participate in this two-centred mixed method study incorporating an RCT and qualitative analysis

5 in a triangulation design. This approach was selected as it was considered to provide a broader

6 understanding (Cresswell 2015) of both the acceptability and the possible effect of the PRCl in this clinical context.

8 In order to support the study design and increase the validity of findings (Lancaster et al. 2004),

9 the research questions to be addressed were articulated as follows:

- How feasible and acceptable were the proposed methods of recruitment, randomisation, intervention and follow up?

- Was it possible to achieve acceptable recruitment and retention rates within each centre, taking into account defined inclusion/exclusion criteria?

- Were the proposed study questionnaires and data collection methods appropriate?

- Were the study time points for questionnaires and use of $\mathrm{PRCl}$ appropriate?

- Was there any preliminary indication of an effect of the PRCI?

A second component of the study was a qualitative process evaluation (QPE) that aimed to explore in depth women's subjective experience of the study intervention and research methods to provide information to refine any aspects of the research design (if appropriate). The study protocol and methodology employed in this qualitative element has been previously published elsewhere (Bailey et al. 2015)

Prior to commencing recruitment to this study, full ethical approval was given from the NHS Health Research Authority on $21^{\text {st }}$ October 2013 (IRAS project ID 129379). This study was registered with the ISRCTN (trial registration number ISRCTN43571276).

The Intervention

The PRCI (Figure 1) is a theoretically derived and short coping intervention with proven reliability and validity, based on the concept of positive reappraisal (Lancastle and Boivin 2008; Ockhuijsen et al. 2013b; Ockhuijsen 2014; Domar et al. 2015). It aims to promote positive re-evaluation of a challenging situation and consists of a small card containing 10 positive reappraisal statements that encourage users to redefine the waiting period more positively. An accompanying leaflet provides concise guidance on the use of the PRCI. Specifically, participants are encouraged to read the card at least twice a day, in the morning and the evening and any other time they feel the need. The guidance also advises that thinking about the positive aspects of a difficult situation does not mean pretending that 'everything is wonderful' when this is not the case, or ignoring the negative aspects of the situation, but taking account of positive aspects alongside the negative. 
3 The study population consisted of patients attending the Recurrent Miscarriage Clinic (RMC) and

4 the Early Pregnancy Unit (EPU) at two tertiary referral hospitals in the United Kingdom. Site A

5 operated a weekly RMC through which potential participants were identified and In Site B, access

6 to potential participants was achieved through the site's EPU. Review of referral rates prior to

7 recruitment suggested that approximately five eligible women would be seen in each centre per

8 month.

9 Inclusion / Exclusion Criteria

11 All women who attended the RMC in Site A and the EPU in Site B who had experienced three or 12 more miscarriages were eligible to participate. Exclusion criteria included if the woman was 13 unable to speak English well enough to understand the study materials, required fertility 14 treatment to achieve a pregnancy, was less than 18 years of age or unable to provide written 15 consent to take part in the study.

16 Study Sample

18 The PRCI has only been previously applied in the context of recurrent miscarriage in one study 19 (Ockhuijsen et al. 2015). This did not yield effect size, therefore, no clinical data was available on 20 which to base a power calculation for the current study. Indeed one of the aims of the present 21 feasibility study was to generate data that could inform a power calculation. Therefore, more pragmatic considerations were used to determine a sample capable, for example, of showing likely rate of referral of participants and feasibility of recruiting adequate numbers in a future definitive trial. It was estimated that the two study sites would yield a total of six patients a month (three from each centre) over a recruitment period of one year. The aim was to randomise 50 participants within this time.

For entry in to the QPE, participants were selected purposively from those who had previously taken part in the RCT component of the study. Characteristics considered in the purposive sampling method were intended to produce a heterogeneous sample, and therefore included previous study group (intervention or control), ongoing pregnancy or miscarriage, ethnicity of participant, age and number of previous live births. Fourteen participants were recruited to the QPE at which point data saturation was achieved.

Eligible participants were given a Patient Information Sheet (PIS) containing study information, by 
1 they had completed their consultation. If patients were interested in finding out more about the

2 study, a meeting was arranged for detailed discussion with the researcher. Although potential

3 participants were free to take as much time as they wished to consider their participation in the

4 study, they were asked to consent to participation prior to becoming pregnant.

5 After providing consent the research participants were asked to notify the researcher of a positive 6 pregnancy test in order to enable randomisation, the aim being to achieve randomisation on the 7 same day as the positive pregnancy test or as soon as possible after this.

8 Randomisation into the two study groups (intervention and control) was carried out using an

9 independent computerised randomisation system with a randomly sized block design with block

10 sizes of 2, 4 and 6. The study population was stratified for those women receiving concurrent

11 medical treatment for RPL, those with underlying medical conditions that were causative of RPL

12 and number of previous miscarriages. The PRCl group were asked to use the intervention and

13 received a weekly questionnaire assessment from the date of a positive pregnancy test until

14 twelve weeks of pregnancy. The control group received the same weekly questionnaire

15 assessment from the date of a positive pregnancy test until 12 weeks of pregnancy, but not the

$16 \mathrm{PRCl}$. All study materials including the study questionnaires and the $\mathrm{PRCl}$ were posted to the

17 participant at randomisation. If a participant experienced a further miscarriage during the study

18 period, they were asked to notify the researcher and were advised to discontinue completing

19 study questionnaires after their miscarriage. Prior questionnaire data from women who

20 experienced miscarriage before twelve weeks of pregnancy was included in the data analysis as

21 for those whose pregnancies continued.

22 Participants became eligible to take part in the QPE if they reached twelve weeks of pregnancy,

23 had used the PRCl and completed the weekly questionnaire assessment, or in the case of the

24 control group, if they had completed weekly questionnaire assessments. If a participant

25 experienced a further miscarriage, they were still approached and invited to take part in an

26 interview. In all cases, the participant contacted the researcher directly to inform them of their

27 miscarriage and it was at this point they were invited to participate in the QPE.

28 Participants indicated on the consent form of the RCT feasibility component of this study whether

29 they would be willing to be invited to take part in the qualitative interviews. Potential participants

30 for the qualitative interview were then selected purposively from the cohort of patients who

31 indicated a willingness to participate. The aim of the purposive sampling was to ensure that

32 perspectives were collected from as diverse a group as possible.

33 Data Collection 
This questionnaire was specifically designed for use in this study to capture relevant baseline

2 demographic information including age, level of education, medical and psychological history (to

3 identify any co-morbidities associated with RPL), gynaecological and reproductive history (fertility

4 history, dates and number of live births and miscarriages) and the time period the woman had

5 been trying to achieve a successful pregnancy.

6 Outcome Measures

8 To assess psychological well-being in women in each study group, two validated outcome measure questionnaires, the Hospital Anxiety Depression Scale (HADS) (Zigmond and Snaith 1983) and the Daily Record Keeping Form (Boivin and Takefman 1995) were used at specific time points. Time points commenced on the day of a positive pregnancy test (or as soon as possible thereafter) and then at weekly intervals until the woman either reported a further miscarriage or reached 12 weeks gestation when ongoing viability is associated with a greater than $95 \%$ chance (Tong et al. 2008) of reaching live birth.

Hospital Anxiety Depression Scale

The HADS and associated questionnaire has been shown to be a valid measure of the severity of anxiety and depression and of changes in a patient's emotional state (Zigmond and Snaith 1983). The questionnaire consists of 14 items (seven questions for anxiety and seven for depression) which are rated on a four-point Likert scale. The anxiety and depression scores are interspersed within the questionnaire, but are scored separately and are interpreted in ranges 0-7 (normal), 810 (mild), 11-14 (moderate) and 15-21 (severe).

Daily Record Keeping Form

The Daily Record Keeping Form (DRK) was used to assess the emotions, appraisals, coping and physical symptoms experienced during the waiting period. The original measure was developed to assess these elements during the waiting period prior to a pregnancy test after fertility treatment (Boivin and Takefman 1995; Boivin and Lancastle 2010).

To adapt the DRK for use in this study, a number of relevant words and phrases were changed to better reflect the waiting period experienced by RPL patients. However, the overall format of the questionnaire was not amended. Furthermore, to reduce the burden of daily monitoring and potential reactivity identified in previous studies (Ockhuijsen 2014), the DRK was completed only at weekly intervals. To avoid confusion for research participants, it was called the 'Weekly Record Keeping Form' for the duration of the study. 
face-to-face, semi-structured interviews that took place at a convenient place and time for the participant. The interviews followed a guide to steer the general direction of data collection and

3 this was developed and based upon the feasibility aims of the study, a review of current literature

4 and discussion with Patient Public Involvement (PPI) representatives and the study supervisory

5 team. The interviews were scheduled to last for between thirty and sixty minutes.

6 Data Analysis

8 Descriptive statistics were used to explore the feasibility of the study processes (numbers of 9 eligible women, recruitment and retention rates, missing data) for each centre. Scores from 10 psychological well-being measures and data from the DRK were summarised and changes over 11 the course of the study examined informally by study statistics and via graphical displays. The 12 relationships between physical symptoms, psychological well-being and coping were explored, 13 again through informal methods, such as graphical displays. An informal assessment of any 14 indication of intervention effect was considered, however the purpose of this study was not hypothesis testing but feasibility and acceptability.

QPE interviews were audio recorded and then transcribed verbatim, aiming to achieve transparency by maintaining memos, field notes and a reflective diary during the process. Two members of the research team completed the initial coding of the raw data and developed the initial themes and this was discussed with other members of the research team who examined the transcripts and were asked to compare their perceptions of the interview data. The data was analysed utilising the general inductive approach (Thomas 2006). The main analytic strategy of this approach was to establish the core meanings evident in the text, which were relevant to the evaluation (or research) objectives.

Although findings from the quantitative and qualitative analyses are presented concurrently in this paper, fuller details of the qualitative methodology and findings are reported elsewhere (Bailey et al. 2015; Bailey et al. 2019)

\section{Patient and Public Involvement}

A Patient and Public Involvement (PPI) advisory group supported this research and met on a regular basis for the duration of this study. The group were involved with the design of the study and commented on any potential burden of participation in the study from a patient's perspective. The group were involved with data interpretation, and, at the end of the study, commented on the findings and contributed to the dissemination plan. 
3 The specific structure previously proposed for reporting findings of feasibility studies (Lancaster et

4 al. 2004; Eldridge et al. 2016) was applied.

5 Recruitment-Related Feasibility Outcomes

7 In total, 118 women were assessed for eligibility to participate in the study in Site A of whom 19

8 did not meet eligibility criteria. Of the 99 women approached to participate in Site A, 6 (6.0\%)

9 declined to participate; contact was lost with 26 (26.3\%) women who either failed to notify the

10 researcher whether they had decided to take part in the study or the researcher was unable to

11 contact them. A total of 75 participants were recruited to the study, 67 (89.3\%) of these were

12 from Site A where recruitment targets were exceeded. In contrast, in Site B, the number of

13 women identified as potential participants fell well below the expected number, with a marked

14 discrepancy between the estimated and actual recruitment rate. Despite an extended recruitment

15 period and the provision of research infrastructure support systems, recruitment remained

16 difficult at this site.

17 Baseline demographic characteristics of the recruited and randomised participants are shown in

18 Table 1.

19 Participant recruitment and flow through the study and reasons for exclusions are outlined in the

20 CONSORT diagram in Figure 2. No data relating to the proportion of patients who were

21 approached and declined to participate or were not eligible were available from Site B.

22 All 14 women who participated in the QPE (for sample characteristics see Table 2 ) reported a

23 positive attitude to taking part in the research and felt comfortable with the way they were

24 approached and invited to participate in the research study. The participants commented that

25 they considered this an important area of research and findings suggest that this group of women

26 were altruistic, keen and willing to participate in research that would help women in a similar

27 situation to themselves, even if it did not help them personally (see Figure $3 \mathrm{~A}$ ).

\section{Randomisation- Related Feasibility Outcomes}

Between February 2014 and March 2016 a combined site total of 47 participants (62.7\% of 
statistician confirmed that the computerised randomisation system worked efficiently. After

2 randomisation, study materials (study questionnaires and PRCl if allocated) for the control and

3 intervention groups were posted to the woman within 48 hours of her notifying the researcher of

4 a positive pregnancy test. Study participants found both the concept and process of

5 randomisation acceptable.

6 In the QPE all respondents noted that they had understood the notion of randomisation as

7 described in the PIS. Two interview participants who were randomised to the control group

8 voiced some disappointment that they had not received the study intervention. However, the fact

9 that this study included an element of randomisation did not affect participants' willingness to

10 participate in the study (see Figure 3B).

11 Study Questionnaires - Related Feasibility Outcomes

Study participants completed this form at the time of recruitment. Questions were answered in an appropriate way and completed correctly, suggesting that the questionnaire was easy to use for the participant and that there were no general comprehension difficulties.

The Hospital Anxiety Depression Scale

Study participants were asked to complete the questionnaire on eight occasions at weekly intervals from a positive pregnancy test (normally around 4 weeks of pregnancy) until 12 weeks of pregnancy (but to discontinue its use if they experienced a further miscarriage). Study findings suggest that there were no identified difficulties with comprehension of the questionnaire wording or scoring. Questionnaires were provided in a paper format and participants were asked to return them in a prepaid envelope. Returned questionnaires were all completed correctly, there were no missing data and the forms were completed according to guidance.

Weekly Record Keeping Form

Participants were requested to complete this questionnaire weekly, alongside the HADS, until 12 weeks of pregnancy (but to discontinue if they experienced a further miscarriage).

The study highlighted some issues with the rating scale of the WRK form; the rating scale descriptors reflected different levels of negative impact meaning that it was not possible to rate the positive emotions such as 'happy' and 'hopeful' in an appropriate way. However, the QPE demonstrated that participants in this study chose to rate the positive emotions by scoring the intensity with which they felt it, rather than the degree to which it had a negative impact. The WRK also instructed participants to leave the score box 'blank' if an emotional or physical 
symptom had not been experienced. This made it difficult to differentiate between a blank score or failure to answer that question. The WRK should be amended to address both of these issues.

3 Overall, participants found the WRK a helpful and supportive questionnaire and interviewees

4 shared numerous positive reflections on the impact of the WRK that suggested an effect

5 additional to any effect of the PRCI. Participants appeared to view the questionnaires as a form of 6 intervention, suggesting that completion of the questionnaires may have promoted psychological well-being. The self-adaptation of the questionnaires into an intervention and source of support appeared to focus on two main areas. Study participants used the questionnaires as a tool to help reflect on the difficult emotions they were experiencing during the waiting period, encouraging an awareness of their emotions, anxieties and feelings, and utilised the weekly completion of them as a method of monitoring the pregnancy's progression (see Figure $3 \mathrm{C}$ ).

Intervention - related Feasibility Outcomes

It was important in this study to determine the acceptability of the intervention for use by women with RPL as there was a potential that participants would find the use of this self-administered intervention unacceptable. The study PIS introduced the concept of positive reappraisal and participants were given the opportunity to ask questions regarding this at the time of consent. No potential participants expressed concerns or declined taking part in the study as a result of a coping intervention being tested and all seemed amenable to the idea of using the PRCl.

Participants who received the PRCl were asked to read and reflect upon it at least twice a day and to record how often they actually used it during the previous week when they completed the WRK. An important aspect of assessing the feasibility and acceptability of the intervention was to determine frequency of use of the intervention and descriptive statistics were used to show this. Answers on the WRK indicated that all women used the PRCl but there was some variation in the frequency of its use as illustrated in Figure 4.

Qualitative feedback from the QPE contributed significantly to understanding the participants' perceptions of the PRCI. During the interview, women were asked to comment on the practicalities of using the intervention and to share their personal reflections of using it.

First impressions and initial reactions to the PRCl suggested a degree of scepticism as to how such a simple intervention could help in the management of their anxiety. But, overall there was a positive attitude and willingness to engage and participants appeared agreeable to continue with the intervention (see Figure 3D). varied considerably with some interviewees stating that they used the card more at the beginning of the waiting period and others suggesting they used it more as the pregnancy continued as they 
1 became more familiar with the intervention and concept of positive reappraisal. However,

2 participants individualised how often they used the PRCI frequently utilising the intervention at

3 time points when their anxiety levels were most elevated (see Figure 3E).

4 Despite initial reservations regarding the use of the $\mathrm{PRCl}$, without exception, all of the

5 interviewees offered varied and candid positive perspectives on the use of the intervention. There

6 was a consensus that the PRCI promoted a positive re-evaluation of the waiting period and that it

7 encouraged an appreciation of the positive aspects of their lives and a renewed appreciation of

8 the everyday things in life. These positive aspects had often been forgotten and lost within the

9 overwhelming feelings of anxiety experienced about the new pregnancy.

10 There were mixed accounts of whether the $\mathrm{PRCl}$ actually helped or reduced the anxiety the

11 participants were experiencing. Some women expressed the belief that it had really helped to

12 alleviate their worry and others suggested that the intervention sustained their ability to cope

13 with the continued anxiety during the waiting period (see Figure 3F).

14 This study was not statistically powered to formally calculate the effectiveness of the PRCI in

15 improving psychological well-being of women during the waiting stages of a new pregnancy

16 following RPL. However, the quantitative and qualitative data did make it possible to assess some

17 of the impact of the intervention on measures to be used in a future RCT. Descriptive statistics and graphical displays compared and contrasted anxiety scores within the control and intervention groups to generate data to help inform the power calculation for a definitive clinical

20 study of the PRCI.

21 There were differences in HADS anxiety scores between the intervention and control group as 22 shown in Figure 5. The PRCI group shows an overall downward trend (reducing anxiety levels) as 23 pregnancies progress, reflecting the expectation that anxiety scores would decrease on a weekly 24 basis throughout the waiting period. However, the anxiety scores for the control group were 25 more variable over the eight weeks of questionnaires.

26 Recent publications concerned with ensuring appropriate reporting of feasibility and pilot studies

27 (Shanyinde et al. 2011; Bugge et al. 2013) offer a useful analytic framework for applying

28 methodological issues and summarising findings when assessing feasibility research. Table 3,

29 based on the work of Bugge et al. (2013) summarises the key feasibility findings of this study

30 against the methodological issues for feasibility research. 
3 This study aimed to establish the feasibility and acceptability of conducting a multicentre RCT to

4 test the effects of the PRCl on the psychological well-being of women with RPL. The results

5 provide a number of insights pertinent to the successful design of such a study, and of the likely

6 value of the $\mathrm{PRCl}$ in this clinical context.

7 Successful recruitment to a future definitive study investigating the use of the PRCI with women

8 with RPL is shown to be possible. There is an appropriate and sizeable population willing to

9 participate. However, as with many trials, recruitment at an external site proved more difficult

10 than anticipated at the outset of the study, despite both using the same study protocol. A number

11 of facilitators and barriers to recruitment were identified.

12 Lack of an on-site researcher to act as a champion to promote the research study and no named

13 clinical lead for RPL patients were likely to have contributed to the relative under recruitment at

14 Site B. In addition, because recruitment was taking place on the EPU and not in a specialist RPL

15 outpatient clinic, patients were informed about the study at the time of their miscarriage. This

16 may have discouraged the staff from inviting participation. These findings highlight the need to

17 consider the broader processes of recruiting participants when planning recruitment sites in a

18 future definitive multi-centre study of the PRCI

19 The validation of data collection forms / questionnaires is fundamental to a feasibility study

20 (Lancaster et al. 2004) and this is particularly important when the questionnaires are completed

21 by the participants themselves. This includes ensuring that the selected questionnaires are the

22 most appropriate data collection methods and provide researchers with the information they

23 require.

24 The QPE highlighted a significant feasibility and internal validity issue, focusing particularly on the

25 WRK. This questionnaire was intended as an instrument to measure emotional and physical

26 reactions during the study time-period. However, many participants reported using the

27 questionnaire as a self-monitoring intervention and may have perceived or experienced a positive

28 effect as a result of weekly rating of the emotional and physical reactions listed on the WRK.

29 Self-monitoring refers to assessment procedures that involve data collection by the client

30 (Korotitsch and Nelson-Gray 1999), and provides the user with continuous and immediate

31 feedback on their situation (Bornstein et al. 1986). It has been shown to have therapeutic effects

32 due in part to the reactive effects of the self-monitoring activity (Korotitsch and Nelson-Gray

33 1999).

34 In this feasibility study, the WRK provided study participants with an opportunity to spend time

35 reflecting on the physical and emotional reactions they were experiencing during the waiting

36 period of their new pregnancy. Participants reported this encouraged an awareness of the 
emotions, anxieties and feelings they were experiencing, helping them to rationalise them and giving back some control in a situation where the women felt they had little control over the outcome.

4 The self-monitoring and reactivity effect of the WRK was not altogether surprising. A previous study which first investigated the use of the $\mathrm{PRCl}$ as a self-help coping intervention in women with miscarriage(s) also highlighted the potential reactivity effects of the WRK questionnaire. Specifically, it concluded that women could experience a positive or negative effect as a result of rating their emotions, physical symptoms, appraisal and coping (Ockhuijsen 2014) .

The fundamental issue here appears to be the repeated use of the WRK (daily or weekly), enabling it to act as a self-monitoring technique. From an internal validity point of view, any PRCI benefits may be due to an interaction between the monitoring and the $\mathrm{PRCl}$, rather than the PRCl itself. Indeed, a study by Korotitsch and Nelson-Gray (1999) exploring the concept of selfmonitoring research in assessment and treatment proposed that the reactive effects of selfmonitoring may make an adjunctive contribution to the beneficial treatment effects when used alongside other interventions.

The $\mathrm{PRCl}$ was designed to help women re-interpret the demands of the waiting period in a more positive way (Ockhuijsen et al. 2014b) and the aim of the WRK in this feasibility study was to measure treatment specific reactions to using this by capturing the intervention's weekly effects. However, it seems evident that the weekly monitoring and associated reactivity to the WRK in itself have had an impact on the reporting of emotional and physical reactions. A future definitive study of the $\mathrm{PRCl}$ would need to pay careful consideration to how to disentangle this 'methodological artefact' (Ockhuijsen 2014) and the effects of the PRCl to ensure the internal validity of any future study. Ockhuijsen et al. (2014a) showed that when the PRCl is used alone it demonstrates greater benefits than when combined with monitoring (on quantitative measures).

Although previous studies had shown no detrimental side effects of the PRCI (Lancastle and Boivin 2008; Ockhuijsen et al. 2013b; Ockhuijsen et al. 2014b), establishing the acceptability of the intervention to women with RPL was an important consideration of this study. Indeed, Sekhon et al. (2017) propose that determining acceptability has become an important consideration in the design, evaluation and implementation of health care interventions. Successful implementation of an intervention, such as the $\mathrm{PRCl}$, depends on the acceptability of the intervention to the recipients. Certainly, there was a concern at the outset of this study that women with RPL may find the concept of positive reappraisal difficult to understand and be sceptical of the value of using a self-managed intervention, given the extreme levels of anxiety and emotional turmoil they experience during the waiting period of a new pregnancy. As such, one of the main objectives of this feasibility study was to assess to what extent the PRCI was judged by women as suitable and 
functional to address their psychological needs and be practical and serviceable to use. In general, the quantitative findings from this feasibility study suggest that participants' willingness to take part in the study and general compliance in using the PRCl is an encouraging sign that women with RPL might be receptive to this intervention.

Graphical presentation of the HADS scores (Figure 5) demonstrated an increase in anxiety levels until week five of the questionnaire (week eight of pregnancy). This may reflect the frequency of miscarriages occurring around this gestation, after which the likelihood of an ongoing pregnancy increases. As pregnancies progress to this stage, participants may have begun to emotionally invest in the pregnancy, and to anticipate anxiety of the grief that would accompany a further miscarriage at this stage.

11 The HADS showed reduced anxiety levels in the PRCI study group. While a previous study has demonstrated a lower anxiety level in women who used the PRCI during the IVF waiting period (Ockhuijsen et al. 2014a), the effects of the PRCl on anxiety levels, were attenuated when combined with daily monitoring of the emotions, which itself was found to have an impact. Consistent with this, the qualitative process evaluation suggested that anxiety levels were reduced as a result of completing the study questionnaires. These observed quantitative effects of the $\mathrm{PRCl}$ could be used to make a power calculation for a future study in which impact on anxiety is the primary endpoint.

Although a previous study of the PRCl during miscarriage waiting periods did not reveal any effect on anxiety (Ockhuijsen et al. 2014b) these participants had no history of recurrent pregnancy loss. In a qualitative study of the perceived usefulness of the $\mathrm{PRCl}$, women with only one past miscarriage did not see the need for such a coping tool, whereas those women with recurrent miscarriage did (Ockhuijsen et al. 2013a). The PRCI might therefore be most useful in those needing to deploy coping effort because their available current coping resources are not sufficient to match the perceived threat (i.e. another miscarriage), resulting in greater levels of anxiety.

Another key study finding was that participants modified the frequency of use of the PRCl, reducing the overall time spent using the $\mathrm{PRCl}$ and decreasing or increasing the number of times per day they read the card, adapting guidance to suit their needs or preference. Participants appeared to base this adaptation on their judgement and perception of the intensity of the emotions (e.g. anxiety, fear and uncertainty) they were experiencing and their assessment of the effect of the intervention on these challenging emotions. For example, some participants elected to utilise the card at times when their anxiety levels were most elevated, using the card more frequently at the beginning of the waiting period and decreasing when they came to feel more confident that the pregnancy would continue. Others increased the use of the PRCl throughout the waiting period as they became familiar with both the card and the process of positive 
reappraisal. Some participants chose to use the $\mathrm{PRCl}$ simply as a method of aiming to manage acute anxiety episodes. Interestingly, there was a general view among the participants that rather than adapting the PRCl guidance, they were personalising the use of the PRCI to suit their

4 individual needs.

5 This observation, which has previously been described (Ockhuijsen 2014; Ockhuijsen et al. 2014b;

6 Ockhuijsen et al. 2015) points to the need to consider how and whether fidelity should be

7 accurately monitored to ensure consistent implementation of the PRCI in a future definitive multi-

8 centre study. It could be that allowing women to individualise their use of the PRCl is likely to

9 increase its effectiveness.

10 A further finding of this study is the large number of variables influencing both the use,

11 interpretation and effects of the PRCI. For example, one person might read the card only once,

12 but it may resonate with her and she keeps the PRCl statements firmly lodged in her memory. The next person may read the card twice a day as requested and start to think differently as a result, but it is a slow process to learn the skill of positive reappraisal. Another person may read it twice a day as requested, like a 'tick box' exercise, but avoid thinking about the concept of positive reappraisal at all, perhaps because it is too far out of her comfort zone and something she has no intention of thinking about. There are many different variants of how women might use and interpret the $\mathrm{PRCl}$, but in terms of broad metrics, simply reading the card does not mean that the person is engaging with positive reappraisal. Indeed, the person who just reads the card once, but its statements resonate with her immediately, may be engaging with positive reappraisal coping most of all.

It appears that in this feasibility study 'engagement' and 'intervention fidelity' refer to far more than twice daily reading the $\mathrm{PRCl}$ and compliance with the guidelines for use. Given that it is a self-help intervention involving thinking and personal interpretation, it is difficult to measure, control or have insight into how participants precisely used it and this may be a limitation of the intervention and of this feasibility study.

The only quantitative measures of use of the $\mathrm{PRCl}$ in the current feasibility study were in the WRK questionnaire. Although the QPE added to the understanding of acceptability of the PRCI, it could have extended assessment of the intervention by asking participants in more detail about how and in what ways they tried to positively reappraise the situation (if at all) and about whether they felt that their coping strategies had improved as a result of the PRCI. Previous quantitative research does show that using the guidance as provided to participants in the present study does increase ability to use positive reappraisal coping as measured by another unrelated measure (Domar et al. 2015). However, more in-depth understanding of how the PRCl sustains coping could be a target for future research. 
2 A key strength of this study is that its development and protocol was guided by an active PPI

3 advisory group and this ensured the patient's perspective was central to the study. Study

4 limitations included the fact that the majority of participants who took part in this study were of

5 White British ethnicity, mainly due to the location of the study sites in the South of England. A

6 more varied ethnicity sample may have provided a more diverse and richer insight into the

7 cultural effects of RPL

8 In conclusion, this study successfully met its original objective determining that an effectiveness

9 RCT of the $\mathrm{PRCl}$ is possible; it also highlighted specific feasibility issues (for example around

10 recruitment and study outcome measures) that require further consideration in the planning of a

11 definitive study. However, study participants engaged with the $\mathrm{PRCl}$, were receptive to it and

12 appeared to experience benefits from its use with no apparent downside. Furthermore, the cost

13 of the $\mathrm{PRCl}$ is negligible in terms of both resources and finances. The study raises the important

14 question of whether a future definitive multicentre RCT of the $\mathrm{PRCl}$ is justified given the

15 substantial investment of finances and time this would require. The demand for healthcare

16 continues to grow and public health systems are challenged to provide high quality, effective care

17 within limited resources. With that in mind, evidence generated in this study suggests that this

18 model of care might already have the potential to be made more widely available as a safe, low

19 cost, convenient and easily deliverable intervention to provide much needed support to a

20 vulnerable patient population. Future research will focus on technically innovative strategies to

21 develop and deliver a supportive package of care, of which the PRCl will be an important

22 component, to support the psychological well-being of women with RPL.

23 Acknowledgements

The authors would like to thank the women who kindly agreed to participate in this study and the members of the Patient and Public Involvement group for their valuable input into this

27 programme of research.

Declarations of interest: None

31 This work was supported by the National Institute for Health Research UK (award reference

32 number CDRF-2012-03-004)

33 Trial Registration number

34 ISRCTN43571276 


\section{References}

Bailey S, Bailey C, Boivin J, Cheong Y, Reading I and Macklon N (2015) A feasibility study for a randomised controlled trial of the Positive Reappraisal Coping Intervention, a novel supportive technique for recurrent miscarriage. BMJ open 5:e007322. doi:10.1136/bmjopen2014- 007322

Bailey S, Boivin J, Cheong Y, Kitson-Reynolds E, Bailey C and Macklon N (2019) Hope for the best ... but expect the worst: a qualitative study to explore how women with recurrent miscarriage experience the early waiting period of a new pregnancy. BMJ Open 9:e029354(doi:10.1136/bmjopen-2019-029354)

Boivin J and Lancastle D (2010) Medical waiting periods: imminence, emotions and coping. Women's health (London, England) 6(1): 59-69

Boivin J and Takefman JE (1995) Stress level across stages of in vitro fertilization in subsequently pregnant and nonpregnant women. Fertility and Sterility 64(4): 802-810

Bornstein P, Hamilton S and Bornstein M (1986) Self-monitoring procedures IN: Ciminero K, Calhoun $\mathrm{H}$ and Adams $\mathrm{H}$ (eds) Handbook of Behavioural Assessment (Second edition Edition). New York: Wiley

Bowen DJ, Kreuter M, Spring B, Cofta-Woerpel L, Linnan L, Weiner D, Bakken S, Kaplan CP, Squiers L, Fabrizio C and Fernandez M (2009) How We Design Feasibility Studies. American Journal of Preventive Medicine 36(5): 452-457

Bugge C, Williams B, Hagen S, Logan J, Glazener C, Pringle S and Sinclair L (2013) A process for Decision-making after Pilot and feasibility Trials (ADePT): development following a feasibility study of a complex intervention for pelvic organ prolapse. Trials 14: 353-353

Craig P, Dieppe P, Macintyre S, Michie S, Nazareth I and Petticrew M (2013) Developing and evaluating complex interventions: The new Medical Research Council guidance. International Journal of Nursing Studies 50(5): 587-592

Cresswell J (2015) A Concise Introduction to Mixed Methods Research Los Angeles: Sage Publishing

Domar A, Gross J, K R and Boivin J (2015) Exploratory randomized trial on the effect of a brief psychological intervention on emotions, quality of life, discontinuation, and pregnancy rates in invitro fertilization patients. Fertility and Sterility 104(2): 440-451

Eldridge SM, Chan CL, Campbell MJ, O'Cathain A, Bond CM, Hopewell S, Thabane L, Lancaster GA, Altman D, Bretz F, Campbell M, Cobo E, Craig P, Davidson P, Groves T, Gumedze F, Hewison $J$, Hirst A, Hoddinott P, Lamb SE, Lang T, McColl E, Shanahan DR, Sutton C and Tugwell $P$ (2016) CONSORT 2010 statement: Extension to randomised pilot and feasibility trials. BMJ (Online) 355

ESHRE (2017) Recurrent Pregnancy Loss. Guideline of the European Society of Human Reproduction and Embryology.

Korotitsch WJ and Nelson-Gray RO (1999) An Overview of Self-Monitored Research in Assessment and Treatment. Psychological Assessment 11(4): 415

Lancaster GA, Dodd S and Williamson PR (2004) Design and analysis of pilot studies: recommendations for good practice. Journal of Evaluation in Clinical Practice 10(2): 307-312

Lancastle D and Boivin J (2008) A feasibility study of a brief coping intervention (PRCl) for the waiting period before a pregnancy test during fertility treatment. Human Reproduction 23(10): 22992307

Moore GF, Audrey S, Barker M, Bond L, Bonell C, Hardeman W, Moore L, O'Cathain A, Tinati T, Wight D and Baird J (2015) Process evaluation of complex interventions: Medical Research Council guidance. BMJ: British Medical Journal 350(h1258): 1-7

O'Cathain A, Hoddinott P, Lewin S, Thomas K, Young B, Adamson J, Jansen Y, Mills N, Moore G and Donovan J (2015) Maximising the impact of qualitative research in feasibility studies for randomised controlled trials: guidance for researchers. Pilot and Feasibility Studies 1(32) 
Ockhuijsen H (2014) A Novel Intervention for Medical Waiting Periods in IVF and Early Pregnancy Unpublished PhD thesis Utrecht, The Netherlands University

Ockhuijsen H, van den Hoogen A, Eijkemans M, Macklon N and Boivin J (2014a) Clarifying the benefits of the positive reappraisal coping intervention for women waiting for the outcome of IVF. Human Reproduction 29(12): 2712-2718

Ockhuijsen H, van den Hoogen A, Eijkemans M, Macklon N and Boivin J (2014b) The impact of a selfadministered coping intervention on emotional well-being in women awaiting the outcome of IVF treatment: a randomized controlled trial. Human Reproduction 29(7): 1459-1470

Ockhuijsen HDL, Boivin J, van den Hoogen A and Macklon NS (2013a) Coping after recurrent miscarriage: uncertainty and bracing for the worst. Journal of Family Planning \& Reproductive Health Care 39(4): 250-256

Ockhuijsen HDL, van den Hoogen A, Boivin J, Macklon NS and de Boer F (2014c) Pregnancy After Miscarriage: Balancing Between Loss of Control and Searching for Control. Research in Nursing and Health 37(4): 267-275

Ockhuijsen HDL, van den Hoogen A, Boivin J, Macklon NS and de Boer F (2015) Original Article: Exploring a self-help coping intervention for pregnant women with a miscarriage history. Applied Nursing Research 28: 285-292

Ockhuijsen HDL, van den Hoogen A, Macklon NS and Boivin J (2013b) The PRCl study: design of a randomized clinical trial to evaluate a coping intervention for medical waiting periods used by women undergoing a fertility treatment. BMC Womens' Health

RCOG (2011) The investigation and treatment of couples with recurrent first-trimester and secondtrimester miscarriage.

Sekhon M, Cartwright M and Francis J (2017) Acceptability of health care interventions: an overview of reviews and development of a theoretical framework. BMC Health Services Research 17(88)

Shanyinde M, Pickering RM and Weatherall M (2011) Questions asked and answered in pilot and feasibility randomized controlled trials. BMC Medical Research Methodology 11(117): 14712288

Thomas DR (2006) A General Inductive Approach for Analyzing Qualitative Evaluation Data. American Journal of Evaluation 27(2): 237-246

Tong S, Kaur A, Walker S, Bryant V, Onwude J and Permezel M (2008) Miscarriage risk for asymptomatic women after a normal first-trimester prenatal visit. Obstetrics and Gynaecology 111(3): 710-714

Zigmond AS and Snaith RP (1983) The Hospital Anxiety and Depression Scale. Acta Psychiatrica Scandinavica 67(6): 361

Figure Legends

Figure 1: The Positive Reappraisal Coping Intervention

Figure 2: Study CONSORT flow diagram

Figure 3: Qualitative process evaluation interview extracts

Figure 4: Frequency of usage of $\mathrm{PRCl}$ during eight weeks of study (weeks 4-12 of pregnancy)

Figure 5: Comparison PRCl and control group HADS mean scores for anxiety weeks 1-8 of questionnaires (weeks 4-12 of pregnancy) 


\begin{tabular}{|c|c|c|}
\hline Methodological issues & Findings & Evidence \\
\hline $\begin{array}{l}\text { 1. Were women with } \\
\text { recurrent miscarriage willing } \\
\text { to participate in research? }\end{array}$ & $\begin{array}{l}\text { Recurrent miscarriage patients showed a } \\
\text { positive mental attitude to participating in } \\
\text { this research }\end{array}$ & $\begin{array}{l}\text { Women reported they were altruistic, } \\
\text { keen and willing to take part in research } \\
\text { that would help other women, even if it } \\
\text { did not help them personally }\end{array}$ \\
\hline $\begin{array}{l}\text { 2. What factors influenced } \\
\text { eligibility and what } \\
\text { proportion of those } \\
\text { approached were eligible? }\end{array}$ & $\begin{array}{l}\text { Ineligibility to participate was mainly due to } \\
\text { the fact that the patient was already } \\
\text { pregnant, receiving fertility treatment or } \\
\text { already participating in another research } \\
\text { study }\end{array}$ & $\begin{array}{l}118 \text { potential participants were screened } \\
\text { for eligibility in Site A. } 99 \text { of these were } \\
\text { eligible. No data available from Site B }\end{array}$ \\
\hline $\begin{array}{l}\text { 3. Was recruitment } \\
\text { successful? }\end{array}$ & $\begin{array}{l}\text { Recruitment in Site A successful, but fell } \\
\text { below expectations in Site B }\end{array}$ & $\begin{array}{l}\text { Total of } 75 \text { participants recruited ( } 67 \text { in } \\
\text { Site A, } 8 \text { in Site B) }\end{array}$ \\
\hline $\begin{array}{l}\text { 4. Did eligible participants } \\
\text { consent? }\end{array}$ & Good conversion from eligibility to consent & $\begin{array}{l}\text { Only } 6 \text { women declined invitation to } \\
\text { participate in study. Main reason for lack } \\
\text { of conversion was loss of contact } \\
\text { between giving study information and } \\
\text { participants confirming they wished to } \\
\text { participate }\end{array}$ \\
\hline $\begin{array}{l}\text { 5. Were participants willing } \\
\text { to be randomised to control } \\
\text { or intervention group and } \\
\text { did they find the } \\
\text { randomisation process } \\
\text { acceptable? }\end{array}$ & $\begin{array}{l}\text { Participants found the concept and process } \\
\text { of randomisation acceptable. }\end{array}$ & $\begin{array}{l}\text { Combined randomisation rate for both } \\
\text { sites } 62.7 \text {. The fact that this study } \\
\text { included an element of randomisation did } \\
\text { not affect the participants' willingness to } \\
\text { take part in the research }\end{array}$ \\
\hline $\begin{array}{l}\text { 6. Were participants } \\
\text { successfully randomised and } \\
\text { did randomisation yield } \\
\text { equality in groups? }\end{array}$ & Randomisation processes worked very well & $\begin{array}{l}\text { Almost equal sized groups. Well balanced } \\
\text { stratification. Study highlighted need to } \\
\text { consider the number of study participants } \\
\text { it would be necessary to recruit in order } \\
\text { to achieve an adequate randomisation } \\
\text { rate - suggest should include a } \\
\text { recruitment target that is at least twice } \\
\text { the randomisation target. }\end{array}$ \\
\hline $\begin{array}{l}\text { 7. Did participant's use the } \\
\text { intervention }\end{array}$ & $\begin{array}{l}\text { Good adherence to overall use of PRCl, but } \\
\text { frequency and mode of use differed to } \\
\text { specific intervention recommendations }\end{array}$ & $\begin{array}{l}\text { Participants reported consistent but } \\
\text { varying use of the PRCI on the WRK } \\
\text { questionnaire. Participants adapted PRCI } \\
\text { use to suit their individual needs }\end{array}$ \\
\hline $\begin{array}{l}\text { 8. Was the intervention } \\
\text { acceptable to the } \\
\text { participants? }\end{array}$ & $\begin{array}{l}\text { Participants demonstrated a positive mental } \\
\text { attitude to using the } \mathrm{PRCl}\end{array}$ & $\begin{array}{l}\text { Only one participant withdrew after } \\
\text { randomisation to intervention. } \\
\text { Participants reported they found the PRCI } \\
\text { an acceptable, practical intervention to } \\
\text { use during the stressful waiting period of } \\
\text { a new pregnancy }\end{array}$ \\
\hline
\end{tabular}




\begin{tabular}{|c|c|c|}
\hline Methodological issues & Findings & Evidence \\
\hline $\begin{array}{l}\text { 9. Were study data } \\
\text { collection questionnaires } \\
\text { completed? }\end{array}$ & $\begin{array}{l}\text { There were excellent completion rates of all } \\
\text { questionnaires. Participants reported they } \\
\text { were happy with returning questionnaires by } \\
\text { post }\end{array}$ & $\begin{array}{l}\text { Only } 4 \text { randomised participants (out of } \\
\text { 47) did not return questionnaires }\end{array}$ \\
\hline $\begin{array}{l}\text { 10. Were the questionnaires } \\
\text { understandable to the } \\
\text { participants? }\end{array}$ & $\begin{array}{l}\text { Participants showed good understanding of } \\
\text { the pre-intervention demographic } \\
\text { questionnaire and the HADS and these were } \\
\text { completed accurately. Issues were raised on } \\
\text { the use of the WRK }\end{array}$ & $\begin{array}{l}\text { Pre-intervention demographic } \\
\text { questionnaire and HADS completed } \\
\text { accurately and in full. The study } \\
\text { highlighted issues with the rating scale on } \\
\text { the WRK (did not allow for the scoring of } \\
\text { positive emotions) and confusion over } \\
\text { whether a blank score box equated to a } \\
\text { zero score or missing data }\end{array}$ \\
\hline $\begin{array}{l}\text { 11. Did the questionnaires } \\
\text { provide the researchers with } \\
\text { the data they required? }\end{array}$ & $\begin{array}{l}\text { Data generated by the study questionnaires } \\
\text { were appropriate and valuable. However, } \\
\text { limited data were generated that specifically } \\
\text { assessed coping and coping strategies }\end{array}$ & $\begin{array}{l}\text { Because of the lack of data generated by } \\
\text { the questionnaires which specifically } \\
\text { assessed coping, it was not possible to } \\
\text { fully assess the effect of the PRCI on } \\
\text { coping mechanisms and strategies }\end{array}$ \\
\hline $\begin{array}{l}\text { 12. Was study retention } \\
\text { good? }\end{array}$ & Retention rates good & $\begin{array}{l}\text { Out of the } 47 \text { randomised participants, } 42 \\
\text { completed the study }\end{array}$ \\
\hline $\begin{array}{l}\text { 13. Were the logistics of } \\
\text { running a multicentre study } \\
\text { assessed? }\end{array}$ & Varying recruitment rates in two study sites & $\begin{array}{l}\text { Differing recruitment success in Site A } \\
\text { and B highlighted issues around } \\
\text { recruitment barriers in different sites } \\
\text { which would need consideration in future } \\
\text { definitive study }\end{array}$ \\
\hline $\begin{array}{l}\text { 14. Did all the components } \\
\text { of the protocol work } \\
\text { together? }\end{array}$ & Protocol components had excellent synergy & $\begin{array}{l}\text { No difficulties were identified in the } \\
\text { various research processes employed in } \\
\text { this study or in the researcher's ability to } \\
\text { implement them. For example, following } \\
\text { recruitment, the randomisation process } \\
\text { worked well and the participant's care } \\
\text { moved forward to the appropriate trial } \\
\text { arm }\end{array}$ \\
\hline
\end{tabular}

Table 2: Key feasibility findings (based on Shandyinde et al 2011 and Bugge et al 2013) 


\begin{tabular}{|l|l|l|l|l|}
\hline Participant & Ethnicity & Age & $\begin{array}{l}\text { Number of previous } \\
\text { miscarriages }\end{array}$ & $\begin{array}{l}\text { Ongoing pregnancy (OP) or further } \\
\text { miscarriage (M) at time of QPE } \\
\text { interview }\end{array}$ \\
\hline 1 & White British & 38 & 3 & OP \\
\hline 2 & White British & 37 & 3 & OP \\
\hline 3 & White British & 42 & 6 & M \\
\hline 4 & White British & 34 & 4 & M \\
\hline 5 & White British & 31 & 4 & M \\
\hline 6 & White British & 39 & 4 & M \\
\hline 7 & White British & 33 & 4 & M \\
\hline 8 & White British & 37 & 3 & OP \\
\hline 9 & Other & 29 & 3 & OP \\
\hline 10 & White British & 38 & 3 & OP \\
\hline 11 & White British & 34 & 4 & OP \\
\hline 12 & White British & 36 & 3 & OP \\
\hline 13 & White British & 40 & 4 & M \\
\hline 14 & White British & 34 & 3 & OP \\
\hline
\end{tabular}

Table 2: Sample characteristics of QPE participants. 


\begin{tabular}{|c|c|c|c|}
\hline & Recruited Participants ( $n=75)$ & $\begin{array}{l}\text { Control group } \\
(n=23)\end{array}$ & $\begin{array}{l}\text { PRCl group } \\
(n=24)\end{array}$ \\
\hline Mean age (range) & $33.53(19-44)$ & $33.91(19-42)$ & $31.79(20-42)$ \\
\hline $\begin{array}{l}\text { Ethnic Group n (\%) } \\
\text { White British } \\
\text { Other } \\
\text { Missing Data }\end{array}$ & $\begin{array}{l}69(92) \\
5(6.6) \\
1(1.3)\end{array}$ & $\begin{array}{l}23(100) \\
0 \\
0\end{array}$ & $\begin{array}{l}21(87.5) \\
3(12.5) \\
0\end{array}$ \\
\hline $\begin{array}{l}\text { Level of Education } \\
\mathbf{n}(\%) \\
\text { None } \\
\text { GCSE / O Levels } \\
\text { A Levels } \\
\text { Higher Degree } \\
\text { Other } \\
\text { Missing data }\end{array}$ & $\begin{array}{l}2(2.7) \\
17(22.7) \\
4(5.3) \\
37(49.3) \\
14(18.7) \\
1(1.3) \\
\end{array}$ & $\begin{array}{l}1(4.3) \\
5(21.7) \\
1(4.3) \\
12(52.2) \\
4(17.4) \\
0\end{array}$ & $\begin{array}{l}0 \\
4(16.7) \\
3(12.5) \\
15(62.5) \\
2(8.3) \\
0\end{array}$ \\
\hline $\begin{array}{l}\text { Number of previous } \\
\text { miscarriages } \mathbf{n}(\%) \\
3 \\
4 \\
5 \\
6 \\
7 \\
8 \\
9 \\
10 \\
\text { Missing data }\end{array}$ & $\begin{array}{l}29(38.7) \\
30(40) \\
5(6.7) \\
3(4) \\
3(4) \\
1(1.3) \\
2(2.7) \\
1(1.3) \\
1(1.3) \\
\end{array}$ & $\begin{array}{l}9(39.1) \\
12(52.2) \\
1(4.3) \\
1(4.3) \\
0 \\
0 \\
0 \\
0 \\
0\end{array}$ & $\begin{array}{l}10(41.7) \\
7(29.2) \\
3(12.5) \\
1(4.2) \\
2(8.3) \\
0 \\
0 \\
1(4.2) \\
0\end{array}$ \\
\hline $\begin{array}{l}\text { Already have child } \\
\text { with } \\
\text { partner } \mathbf{n}(\%) \\
\text { Yes } \\
\text { No } \\
\text { Missing data }\end{array}$ & $\begin{array}{l}34(45.3) \\
40(53.3) \\
1(1.3)\end{array}$ & $\begin{array}{l}11(47.8) \\
12(52.2) \\
0\end{array}$ & $\begin{array}{l}11(45.8) \\
13(54.2) \\
0\end{array}$ \\
\hline $\begin{array}{l}\text { Diagnosed medical } \\
\text { reason } \\
\text { for miscarriages n (\%) } \\
\text { Yes } \\
\text { No } \\
\text { Missing data }\end{array}$ & $\begin{array}{l}9(12) \\
65(86.7) \\
1(1.3)\end{array}$ & $\begin{array}{l}1(4.3) \\
22(95.7) \\
0\end{array}$ & $\begin{array}{l}3(12.5) \\
21(87.5) \\
0\end{array}$ \\
\hline $\begin{array}{l}\text { Seen counsellor for } \\
\text { problems } \\
\text { related to } \\
\text { miscarriages n (\%) } \\
\text { Yes } \\
\text { No } \\
\text { Missing data }\end{array}$ & $\begin{array}{l}5(6.7) \\
66(88) \\
4(5.3)\end{array}$ & $\begin{array}{l}2(8.7) \\
21(91.3) \\
0\end{array}$ & $\begin{array}{l}3(12.5) \\
19(79.2) \\
2(8.3)\end{array}$ \\
\hline
\end{tabular}

Table 1: Baseline information and sample characteristics of intervention and control groups 


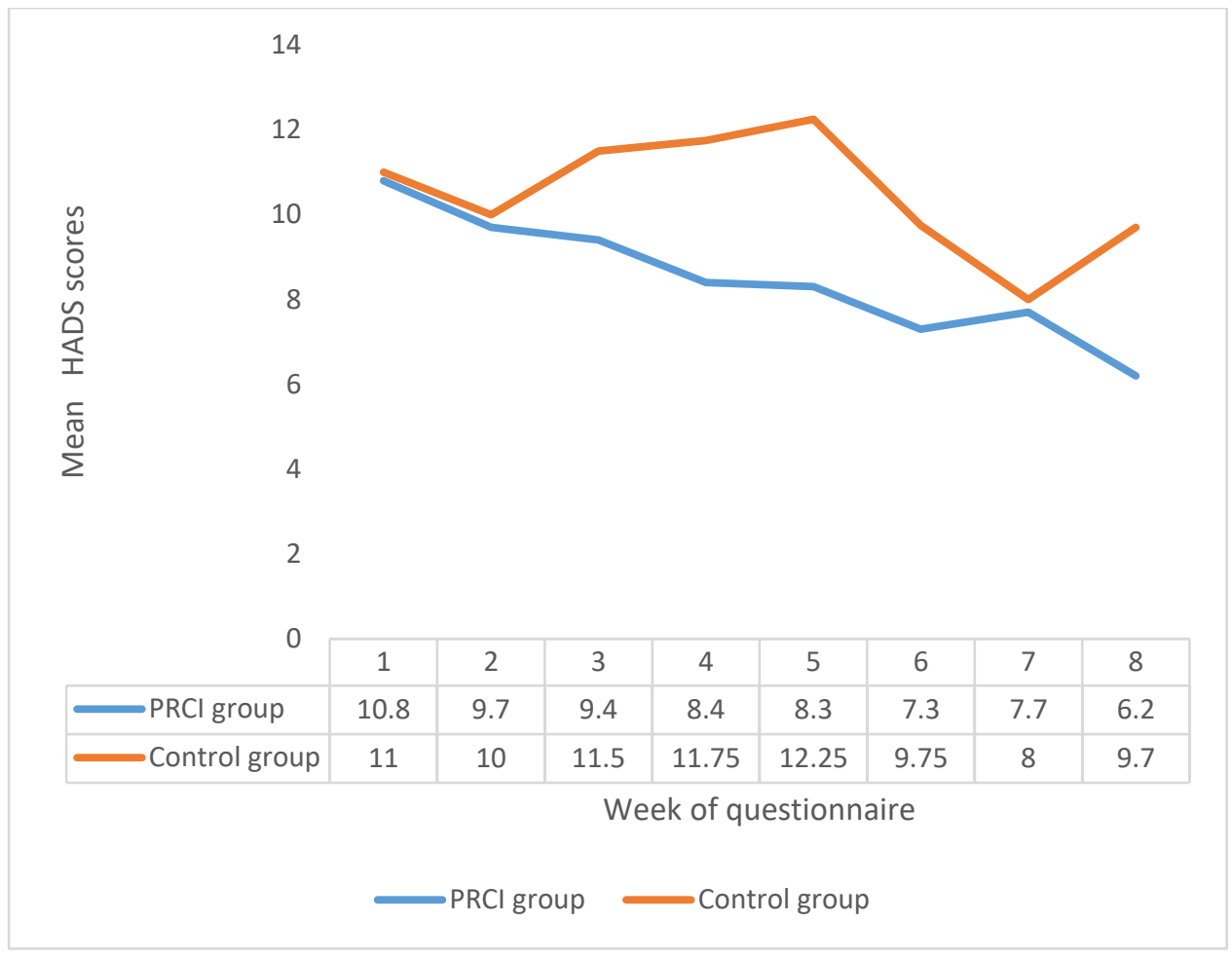




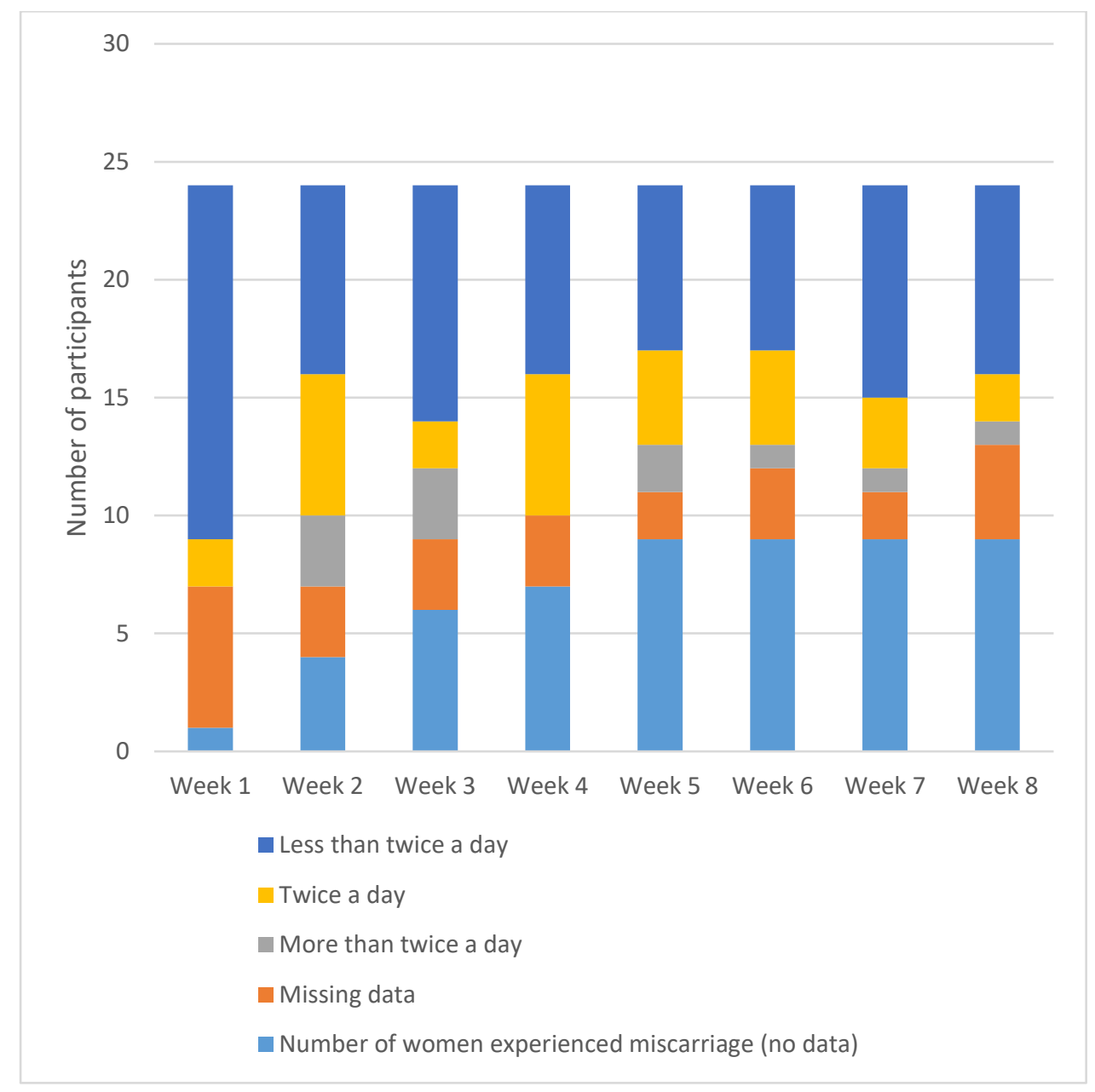


Pane A - Qualitative views on recruitment and study participation

I was very happy to participate, I think it's very important and I think that the topic of the research is very important (Participant $12-3$ miscarriages)

I wanted to be part of something ... and if I was able to help people in the future I was quite positive about that (Participant $11-4$ miscarriages)

Pane B - Qualitative views on the randomisation process

I mean I wanted the card and I was disappointed that I didn't get that group, but I get the point of it all and I know how it works (Participant 8-3 miscarriages)

I was disappointed, I wanted to try something ... but someone always has to be in that group so that's fine. I just wanted to help (Participant $13-4$ miscarriages)

Pane C-Qualitative views on the study outcome measures

I found them helpful in the way that you could just dump on them ... sort of like when people tell you if you've got a problem to write it down and it just gets it out of your head (Participant 6-4 miscarriages)

The questionnaires helped me get through the week, because every time I filled out a new one, I'm like 'well I've just completed a week' and then l'd look at the last ones and the symptoms have changed and the second questionnaire I have filled out seems to be more positive than the last one where I put everything as negative (Participant $9-3$ miscarriages)

Pane D - Qualitative views on the intervention

When I first saw it I actually thought it was a bit awkward. I thought how am going to use this to make myself feel better or remind myself to stay positive? (Participant $9-3$ miscarriages)

When I actually sat down and really thought about each one (the statements on the PRCI) very carefully, it made sense and it really helped me to think about those things (Participant $14-3$ miscarriages)

Pane E - Qualitative views on the frequency of use of intervention

It would suddenly be five am every morning that I was waking up in complete panic, that's the only way I can describe it, then I would have a cup of tea and sit and read the card and think right OK just calm down (Participant 7-4 miscarriages)

Last thing before I go to bed was always a real worry time for me so I would make sure that I read it at least once, sometimes a couple of times.... So what I ended up with was a technique very personal to me (Participant 14-3 miscarriages)

Box F-Qualitative views on psychological impact of intervention

It just made me feel less anxious and made me change how my mind worked really rather than feeling like everything was crashing down (Participant 11 - 4 miscarriages)

It didn't necessarily reduce my anxiety but it did definitely help me cope with the anxious feelings and although it didn't reduce anxiety it made me think more positively so there was still a lot of highs and lows but more highs than I would have had had I not had the technique ... I truly believed it helped me (Participant 14-3 miscarriages)

Actually it really did work, maybe not all the points, but the ones that really made it for me was the think of something positive today ... just trying to find something every day and not looking at next week, or two weeks or three weeks. Let's just focus on today and tomorrow will be another day (Participant $7-4$ miscarriages) 


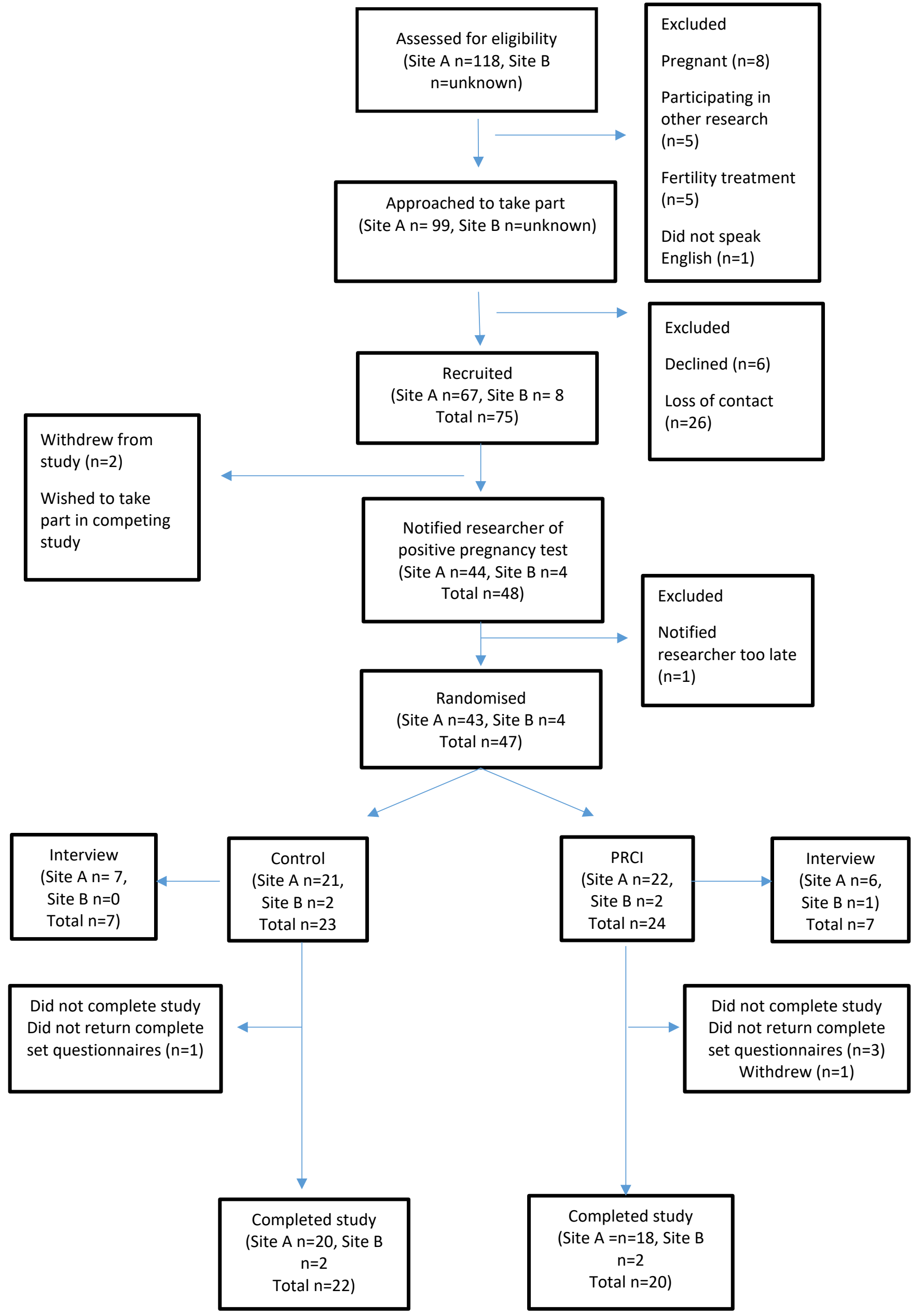




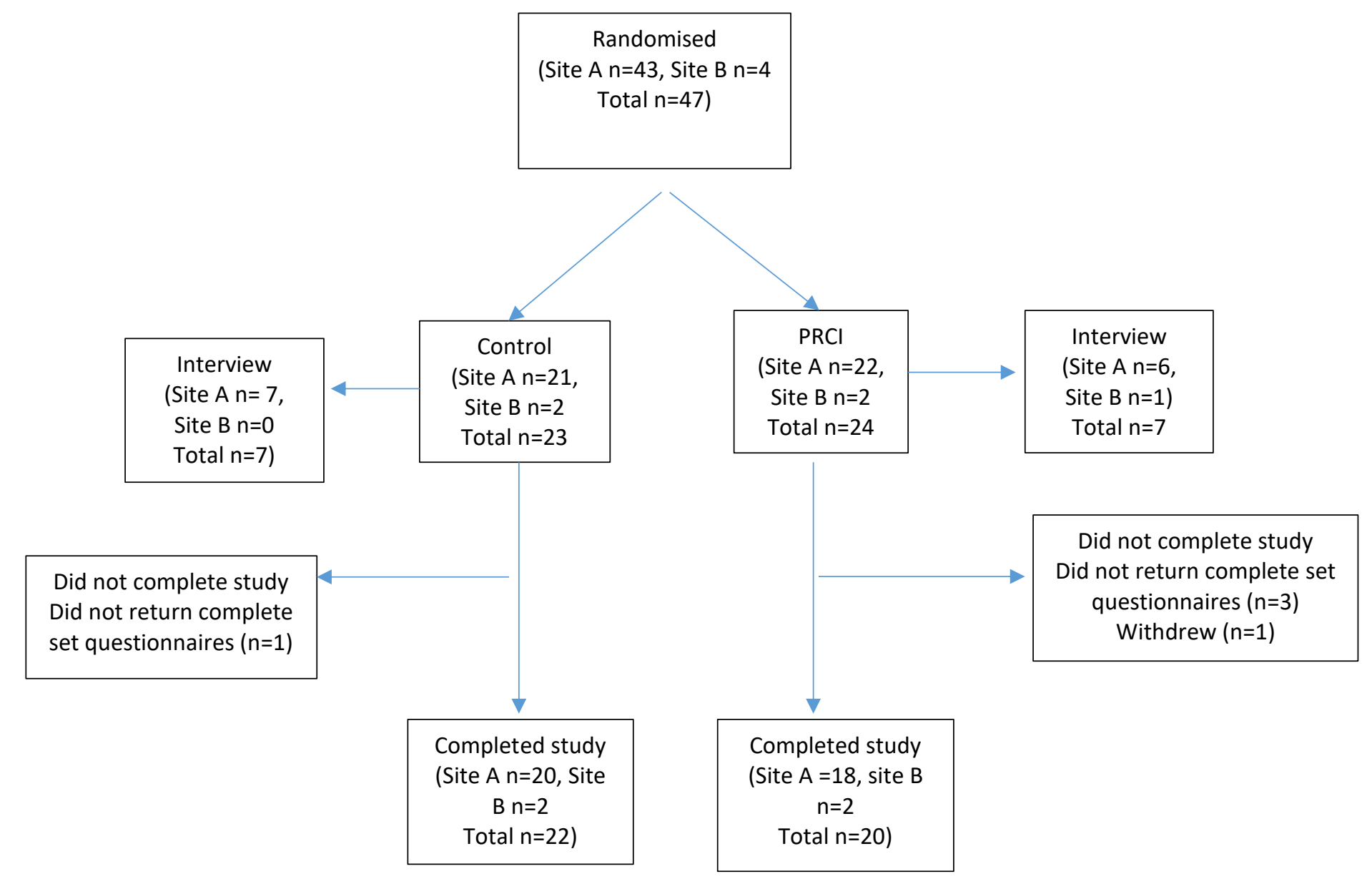




\section{Positive Reappraisal Coping Items (PRCI)}

\section{During this experience I will:}

1. Try to do something that makes me feel positive

2. See things positively

3. Look on the bright side of things

4. Make the best of the situation

5. Try to think more about the positive things in my life

6. Focus on the positive aspects of the situation

7. Find something good in what is happening

8. Try to do something that is meaningful

9. Focus on the benefits and not just the difficulties

10. Learn from the experience

Figure 1: The Positive Reappraisal Coping intervention 